\title{
LA PROTECCIÓN A LOS DERECHOS DEL TRABAJADOR EN EL RÉGIMEN CONCURSAL ARGENTINO. LA PARTICIPACIÓN DE LA COOPERATIVA DE TRABAJO
}

\author{
PROTECTING RIGHTS WORKER IN THE \\ ARGENTINE BANKRUPTCY REGIME. \\ PARTICIPATION OF COOPERATIVE WORK
}

SILVANA SOLEDAD ORTIZ

UNIVERSIDAD DE LA CUENCA DEL PLATA - UCP UNIVERSIDAD NACIONAL DEL NORDESTE - UNNE

ARGENTINA 


\title{
RESUMEN
}

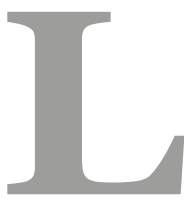

a reforma establecida por la ley 26.684 (B.O 30/07/2011) a la ley 24.522 (07/08/2011), introdujo cambios en relación a los derechos del trabajador en el derecho concursal. La ley fue sancionada el $1^{\circ}$ de junio de 2011 promulgada el 29 del mismo mes y publicada en el Boletín Oficial el día siguiente. La introducción de la cooperativa de trabajo en la ley concursal tuvo lugar en el año 2002 a través de la ley 25.589 aunque de manera escueta en el art. 190. La ley 26.684 tuvo como finalidad proteger al trabajador frente a la insolvencia empresarial otorgándole distintas prerrogativas y una amplia participación en el proceso de concurso y quiebra, mediante la cooperativa de trabajo. Atento a la repercusión que tuvo la mencionada ley en el concursal se analizará a la luz de los principios concursales la implicancia de la participación de la cooperativa de trabajo en el proceso concursal, la finalidad de la ley y la conveniencia del sistema implementado para la protección del crédito laboral frente a la empresa en crisis. Uno de los aspectos que ha sido objeto de observaciones por parte de la doctrina, es que el estado de insolvencia patrimonial en que se encuentra la empresa en crisis hace dificultosa la continuación de su explotación por parte de la cooperativa de trabajo Por ello es necesario reglamentar dichos institutos introducidos en la ley de concurso y quiebras.

Palabras Clave: trabajadores; empresas recuperadas; insolvencia empresaria.

\begin{abstract}
The reform established by law 26,684 (B.O.E 30/07/2011) to law 24,522 (07/08/2011) introduced changes in relation to the rights of workers in the bankruptcy law. The law was enacted on 1 June 2011 promulgated on 29 of the same month and published in the Official Gazette the next day. The introduction of cooperative work in the bankruptcy law took place in 2002 through Law 25,589 although terse way in art. 190. The law 26,684 aimed to protect workers against corporate insolvency giving different prerogatives and broad participation in the process of insolvency and bankruptcy, through cooperative work. Attentive to the impact it had in the bankruptcy system will be analyzed in the light of the principles the implication of the involvement of cooperative work in the bankruptcy process, the purpose of the law and convenience for system the labor protection claim against the company in crisis. One aspect that has been commented on by the doctrine, is that the balance insolvency the company is in crisis makes difficult the continuation of its exploitation by the cooperative work. It is therefore necessary to regulate such institutes introduced in the law of insolvency and bankruptcy.
\end{abstract}

Keywords: trabajadores; empresas recuperadas; insolvencia empresaria. 


\section{1.- ANTECEDENTES}

La reforma introducida por la ley 26.684 (B.O 30/07/2011) a la ley 24.522 (07/08/2011), importó un cambio trascendental en materia de concurso y quiebras. La ley fue sancionada el $1^{\circ}$ de junio de 2011 promulgada el 29 del mismo mes y publicada en el Boletín Oficial el día siguiente. Comenzó a regir en todos los procesos concursales en trámite y en los que se presentaron a partir de su publicación.

En la exposición de motivos del proyecto de ley presentado por el Poder Ejecutivo de la Nación se definió como finalidad del mismo:

“...priorizar la subsistencia de las empresas, para asegurar la continuidad de su producción y la generación de empleos, dando esa posibilidad a las cooperativas de trabajo, de existir, conformada por los mismos obreros que fueron dependientes de las empresas y/o fábricas quebradas”.

Aunque reformas anteriores otorgaron ciertos privilegios a los trabajadores en los procesos de insolvencia tales como la reforma de la ley 25.589 (B.O. 16/05/2002) incorporada normativamente en la legislación en el año 2002 que introduce en la quiebra la presencia de la cooperativa de trabajo. Esta modificación introducida en plena crisis argentina importó una solución temporal, excepcional vinculada a la crisis. (ANICH, 2012, p.14). No obstante ello la reforma del año 2011 significó el afianzamiento de la "cooperativa de trabajo" como el nuevo "ente receptor y continuador" de la actividad y de los bienes de la fallida con ciertas ventajas frente al resto de los acreedores. Otorgándole también ventajas estratégicas al momento de negociar en relación al propio deudor y frente a cualquier sujeto con posibilidades económicas de negociar el lograr el pretendido salvataje empresarial. Ello se advierte con la inclusión del artículo 48 bis en el instituto del salvataje o cramdown empresarial modificando el sistema de la ley 24.522.

Antes de la mencionada reforma, el artículo 189 de la Ley de Concurso y Quiebras establecía un mecanismo de excepción para la continuación de la explotación de la empresa. El principio general era la no continuidad de la actividad. Ello permitía una rápida liquidación del activo falencial, objetivo especialmente buscado por la ley 24522 (Rivera-Roitman-Vítolo, 200o, p. 69). La tutela del interés de los acreedores constituye el valor supremo en esta ley, que revela una nítida alineación ideológica (Iglesias, 1995, p. 1188).

En cuanto a sus antecedentes la ley 24522 había incorporado algunos privilegios al trabajador, el pronto pago laboral fue incorporado por la ley 26086 (B.O. 10/04/2006). Aunque en la práctica esta última reforma no ha significado el cumplimiento de la finalidad perseguida por el legislador, que los trabajadores gocen del privilegio de cobrar sus acreencias mediante un sistema expeditivo que le permita sortear de manera inmediata las consecuencias que la insolvencia empresarial acarrea para el trabajador en relación de dependencia.

Nuestro país siempre se trató el problema del trabajador dentro del proceso concursal y 
no mediante un sistema de leyes colaterales como se han utilizado en el derecho comparado. No obstante ello, se advierte un novedoso antecedente en Argentina con la sanción de la ley 23.472 que modificó la ley de contrato de trabajo creando un Fondo de Garantía de Créditos Laborales sancionada el 31 de octubre de 1986. Esta ley generaba una alternativa de semiexclusión de estos acreedores de la insolvencia, pero nunca fue reglamentada.

Según Vázquez Vialard -para quien la participación de los trabajadores es uno de los temas que más preocupan en la empresa moderna-, de acuerdo con las distintas concepciones socioeconómicas que inspiran su desarrollo, existe una gran gama de posibilidades: desde una cruda concepción capitalista en la que el trabajador no aporta más que su trabajo, hasta aquellas formas en que aquél no sólo debe ser informado sino que además tiene participación en el poder de decisión. (Vazquez Vialard, 2005, p. 122). No obstante ello, frente a la insolvencia empresaria cabría preguntarnos si la participación del trabajador en la posible recuperación de la misma, con las prerrogativas establecidas por ley conviene a los intereses del acreedor laboral, más allá de la finalidad que tuvo en miras el legislador a partir de la reforma de la ley 26.684 .

Cabe resaltar la importancia de la protección del crédito laboral, no sólo dentro del derecho interno, sino por los tratados internacionales y en especial el Convenio de la OIT 173 de 1992, que dispone en el párrafo $1^{\circ}$ del artículo 8:

“...la legislación nacional deberá atribuir a los créditos laborales un rango de privilegio superior al de la mayoría de los demás créditos privilegiados, y en particular a los del Estado y de la seguridad social”.

En este sentido se ha pronunciado la Corte Suprema de Justicia de la Nación en el caso "Pinturas y Revestimientos aplicados S. A. s/quiebra s/recurso de hecho" del 24 de marzo de 2014, en el que decidió por mayoría dejar sin efecto la sentencia dictada por el superior tribunal de la causa (STC) que en el trámite de aprobación de un proyecto de distribución de fondos en una quiebra había desestimado la impugnación deducida por un acreedor laboral por accidente de trabajo a dicho proyecto, donde el 95\% del producido por la venta de un inmueble era afectado al crédito de la AFIP y con el $5 \%$ restante que se le adjudicaba sólo alcanza a cubrir el 7,41 \% de su acreencia. En el mencionado caso no sólo se considera lo establecido por el convenio referido sino también por la Recomendación 180 de la OIT sobre protección del salario (Mansueti, 2014, p. 1523).

La Ley 26.684 prevé una mayor participación de los trabajadores en el proceso (Arts. 14, 29, 42 y 201), amplía y mejora los instrumentos de notificación y posibilita la continuidad de la explotación comercial por parte de la cooperativa de trabajo conformada por ex empleados (Arts. 11, 14, 34); posibilita la adquisición de los bienes con fines productivos compensándolo con la deuda salarial (203 bis) y obliga al estado a brindar asistencia técnica a los procesos de 
recuperación (191bis). En general, introduce una serie de principios del derecho laboral por cuyo conducto ingresan todas las garantías del Art. 14bis de la Constitución Nacional y los tratados internacionales, sumada a una profusa doctrina de la Corte Suprema de Justicia de la Nación (CSJN) en materia de derechos laborales y derechos humanos esenciales que provocan, indefectiblemente, otra interpretación de la norma.

En el año 2015 se debatió a nivel nacional la sanción de la Ley de Economía y Solidaria. Este proyecto de Ley pretende regular, entre otros institutos, a las cooperativas y empresas recuperadas. Regula a las cooperativas de trabajo y crea la figura de la "Sociedad Laboral" como una opción más adecuada a la actividad empresarial. Propone ampliar la Ley de Concurso y Quiebras brindando herramientas para la explotación de empresas recuperadas en manos de cooperativas de trabajo, con la participación del estado, mediante un fideicomiso abierto u otra figura.

\section{2.- COOPERATIVAS DE TRABAJO}

A fin de lograr una comprensión integral de la cuestión planteada cabe conceptualizar a la cooperativa de trabajo; la cual presupone la existencia de un grupo de personas unidas voluntariamente en función de un esfuerzo solidario común. Sin embargo, ostenta ciertas características peculiares que la distinguen de otras organizaciones colectivas. Así, las cooperativas persiguen, como las sociedades, un beneficio económico. No obstante, a diferencia de éstas, no distribuyen dividendos entre los asociados.

De tal modo, en tanto que las sociedades comerciales se constituyen para obtener ganancias con las que se retribuye al capital invertido en ellas, el objetivo que preside la formación de las cooperativas radica en la organización de servicios a favor de sus miembros y de la comunidad. El capital queda subordinado a esa específica finalidad.

La ley 20.337 sobre Cooperativas, en su artículo 2 establece que:

“...las cooperativas son entidades fundadas en el esfuerzo propio y la ayuda mutua para organizar y prestar servicios".

y recepta en los caracteres enumerados allí las notas más importantes y notas universalmente aceptadas por el movimiento cooperativo. Esta ley incluye en su articulado a las cooperativas de trabajo, el que le es aplicable como régimen común. El único elemento que distingue a las cooperativas de trabajo de las demás es su objeto social específico, consistente en brindar ocupación o trabajo a sus asociados (Tevez, 2010, p. 110).

Esta Ley respondió a las pautas establecidas por la OIT en su recomendación $\mathrm{N}^{\circ} 127 / 66$, en el que ese receptaron los principios del movimiento cooperativo, ello es la voluntariedad en 
la agrupación asociativa de sus integrantes, la gestión conjunta y democrática para la satisfacción de objetivos comunes con la consiguiente asunción de una justa participación en los riesgos y beneficios. Y califico a las cooperativas de trabajo como un medio eficaz para mejorar la situación económica y cultural de las personas con recursos y posibilidades limitadas a través del fenómeno del espíritu de iniciativa. Considero que su actividad apareja no solo el incremento de los recursos personales sino también del capital nacional, sobre todo en los países en vía de desarrollo donde permite el progreso económico social y el bienestar de su población.

Surgen así las cooperativas de trabajo como una respuesta superadora del contrato de trabajo que justifica una regulación diferenciada. Las directivas dadas por la OIT ponen de manifiesto la vinculación existente entre el derecho laboral y las cooperativas de trabajo.

En el año 2002, OIT dicta la Recomendación $\mathrm{N}^{\circ} 193$, que modifica la Recomendación $\mathrm{N}^{\circ} 127 / 66$, redefiniendo las cooperativas de trabajo para adaptarlas a las necesidades actuales considerándolas como empresas de autogestión, consistentes en:

"...una asociación autónoma de personas unidas voluntariamente para satisfacer sus necesidades y aspiraciones económicas, sociales y culturales en común a través de una empresa de propiedad conjunta y de gestión democrática".

La legalidad de las mismas se basa fundamentalmente en el respeto y cumplimiento de los principios cooperativos elaborados por el movimiento cooperativo internacional que son los siguientes: adhesión voluntaria y abierta, gestión democrática por parte de los socios, participación económica de los socios, autonomía e independencia, educación, formación e información, cooperación entre cooperativas e interés por la comunidad.

\section{3.- IMPLICANCIAS EN EL SISTEMA Y EN LOS PRINCIPIOS DE DERECHO CONCURSAL}

La legislación concursal responde a valoraciones de la sociedad en un momento determinado. Tradicionalmente el sistema concursal garantizaba el interés del acreedor protegiendo de ésta manera el crédito. Sin embargo en momentos de crisis y tensión social no puede atender a todos los acreedores surgiendo así sistemas que benefician al deudor. Desde la sanción de la ley 19551 en Argentina el derecho concursal propicia como finalidad la conservación de la empresa.

La tutela de la empresa y de su explotación incorpora otros sujetos interesados en el proceso concursal superando la tradicional protección del acreedor y el deudor; considerándose así otros intereses como los de los trabajadores, los proveedores, los clientes, los de la comunidad nacional, regional o local, (por su repercusión en la economía y el empleo) el mercado, el 
estado como acreedor y como proveedor de normas (Conf. Alegría, 2008, pp. 162, 163).

Cabe resaltar que uno de los principios del derecho concursal es la igualdad entre los acreedores pretendiendo que las partes puedan enfrentar la insolvencia patrimonial de su deudor con cierta concordancia. La quiebra es un procedimiento ejecutivo colectivo, dirigido al pago de la masa de los acreedores, según el principio de la igualdad de tratamiento de cada uno de ellos (la llamada par condicio creditorum), mientras la ejecución individual se rige por el diverso principio de la prioridad en el tiempo (al que llega de primero se le paga integralmente, no importa si con exclusión de los demás). La igualdad de tratamiento se manifiesta por múltiples aspectos, pues para aplicarla se prohíbe, ante todo, al acreedor particular ejercitar o proseguir, dese la fecha de la sentencia que declara la quiebra, acciones ejecutivas individuales en relación con el quebrado (Galgano, 1999, p. 205).

Por su parte la discusión sobre la concepción de derecho público y de derecho privado no escapa a la materia concursal. El cuestionamiento sobre los intereses que pretende satisfacer si se conciben como intereses privados y son judicialmente protegidos como intereses de sujetos privados, o si los intereses en juego son, por el contrario, tomados como intereses públicos, o sea como intereses que el Estado hace suyos y para cuya satisfacción, como para cualquier interés público, dirige la acción de sus propios órganos, que, como autoridad, se proponen imponer la realización del interés público y la subordinación del interés privado (Galgano, 1999, p. 199).

En la legislación comparada, en los distintos ordenamientos, se han ido cristalizando conjuntos normativos de estructura heterogénea que persiguen la regulación institucional de estados de crisis de la empresa. Reglas que en algunos países pertenecen a distintas disciplinas y no sólo al derecho concursal (v. gr., también al derecho societario, administrativo y laboral). Su finalidad puede ser la de prevenir la quiebra o afrontar adecuadamente la insolvencia.

El sistema que se elija para afrontar la insolvencia dependerá de las prioridades políticas que se adopten por parte del estado. Según el enfoque ideológico que se dé a la legislación y de la finalidad que tenga la quiebra, resultará aconsejable uno u otro sistema. Conforme se pretenda que la quiebra tenga un fin liquidativo o la preservación de la empresa, se adoptarán distintas instituciones. Por ello la necesidad de adecuar la normativa a los principios y finalidades consideradas por el legislador con una mirada práctica para la eficacia del sistema jurídico.

La insolvencia empresarial se relaciona con algo más complejo que la ley de concurso y quiebras, depende de la cultura, historia, el escenario geográfico, la costumbre y la ética y hasta de la relación de fuerzas generadoras de bienes y servicios que puedan existir en un entorno global. En cada ley hay que descubrir el espíritu, el valor que impone o protege, y el verdadero espíritu puede encontrarse en la ley, fuera de ella o contra ella (Vítolo, 2007, pp. 41 a 43).

El modelo adoptado por el legislador responde a una ideología y a un momento determinado; ideología que se refleja en el modelo económico y las decisiones políticas. La cooperativa de trabajo, como alternativa frente a la insolvencia empresarial, surge frente a la crisis económica Argentina del año 2001, como una alternativa de excepción. Aunque actualmente 
el proceso de concurso y quiebra establece reglas para la intervención de la cooperativa de trabajo aplicable a todos los supuestos.

Parte de la doctrina considera que la intervención del estado es de imprescindible importancia en la regulación de los procesos de insolvencia y se requiere un cambiante enfoque para la solución de las crisis económicas. Conforme Rivera:

“...la renovación permanente de la legislación sobre quiebras y empresas en dificultades no puede sorprender, desde que el derecho de quiebras está directamente influenciado por la evolución de las condiciones económicas; lo que explica que el legislador haya obrado en dos direcciones: reformas en profundidad, que se corresponden a mutaciones fundamentales de la historia económica o del aparato productivo, y reformas puntuales, que aparecen como respuestas a situaciones de crisis más coyunturales”(Rivera, 2006, p. 408).

\section{4.- OTROS SISTEMAS UTILIZADOS PARA RESOLVER LA PROBLEMÁTICA DE LOS TRABAJADORES FRENTE A LA INSOLVENCIA EMPRESARIAL}

El 22 de diciembre de 1986 se crea por ley N 23.472 el Fondo De Garantía De Créditos Laborales. Esta ley, que aún se encuentra vigente, nunca fue reglamentada de modo tal que su aplicación práctica no ha tenido lugar en nuestro derecho. La ley 23.472 disponía la creación de un Fondo de Garantía de Créditos Laborales que se integraría con contribuciones a cargo de todos los empleadores.

Dichos recursos laborales serían destinados a Adelanto a los trabajadores o a sus causahabientes, en su caso, en el supuesto de imposibilidad de pago del empleador. A los efectos de dicha ley se considera que existe imposibilidad de pago del empleador en caso de concurso (concurso preventivo, quiebra, concurso en caso de liquidación administrativa o concurso civil) o de liquidación colectiva judicial de bienes del empleador, cuando así lo declare el juez del concurso o liquidación en razón de que no fuere factible el pago integro de los créditos.

El incumplimiento por el empleador de las obligaciones previstas en la mencionada ley sería sancionado con multa equivalente a cinco veces el monto de la suma que debió depositar, la que sería actualizada de acuerdo con la variación experimentada por el índice de precios al consumidor, nivel general, desde la fecha en que debió efectuar el aporte hasta la de su efectivo pago. Igual actualización corresponderá sobre el aporte omitido y a ella se adicionará un interés del $8 \%$ anual.

El régimen instaurado por esta ley permitía al trabajador hacerse del fondo depositado por su empleador en caso de insolvencia empresaria, cubriendo de esta manera las necesi- 
dades del trabajador frente a la imposibilidad de la empresa de hacerse cargo de las obligaciones laborales.

En caso de incumplimiento de las contribuciones al fondo de garantía por parte del empleador se aplicaría la sanción prevista por la ley, por cuanto debería pagar cuantiosas sumas en concepto de multa.

Como adelantamos, la creación de dicho fondo de garantía nunca fue reglamentado, por cuanto la ley $\mathrm{N}^{\circ} 23.472$ nunca tuvo aplicación práctica.

En 1996 se propuso en la Cámara de Diputados Nacionales la creación del "Fondo de Garantía de Créditos Laborales”. El proyecto establecía que tras el pago, el Consejo Nacional del Empleo, la Productividad y el Salario Mínimo, Vital y Móvil (órgano de aplicación en cuya órbita funcionaría el Fondo), quedaban subrogados en los derechos del trabajador. Este proyecto nunca fue sancionado.

\section{CONCLUSIONES}

Actualmente el sistema concursal argentino otorga prioridad a la continuidad de la explotación de la empresa, ya que en principio, la continuación de la explotación empresaria frente a la quiebra beneficia a todos los acreedores concursales.

La modificación introducida por la ley 26. 684 es de tal profundidad que alteraría la finalidad de liquidación y rápida ejecución de los bienes que consagraba la ley 24. 522, moviendo el eje hacia la protección de los intereses de los sujetos implicados mediante la continuación de la explotación empresaria con preferencia por parte de la cooperativa de trabajo.

Por cuanto la participación de la cooperativa de trabajo en el proceso concursal conlleva a la necesaria intervención del estado en cuanto al apoyo técnico y económico a la cooperativa de trabajo para el cumplimiento de los fines que tuvo en miras el legislador. Protegiendo de esta manera los intereses de los demás sujetos comprendidos en el proceso concursal, entre ellos los acreedores quirografarios - proveedores o clientes sin privilegio concursal - siendo los sujetos mayormente perjudicados por el sistema liquidatorio.

Nuestro sistema jurídico da cuenta de la importancia de la protección a los derechos del trabajador conforme la legislación laboral, la Constitución Nacional, los Tratados Internacionales, Convenios de la OIT, y también sus recomendaciones, acorde fallo de la Corte Suprema de Justicia de la Nación citado ut supra. Esto ha sido receptando en el derecho concursal mediante la reforma del año 2011 que instituye la participación de los trabajadores en la recuperación de los medios de producción y la fuente laboral en caso de proceso concursal o quiebra, importando una afectación a los principios rectores del sistema concursal argentino. 
El sistema implantado por la ley 26.684 dentro del régimen de concurso y quiebras pretende dar respuesta a la necesidad de proteger al acreedor laboral frente a la insolvencia empresaria y priorizar la continuación de la explotación empresaria mediante la participación de la cooperativa de trabajo.

Cabe destacar que la empresa en crisis, en estado de cesación de pagos, carece de crédito, y se encuentra con un patrimonio deteriorado por lo tanto su continuación es dificultosa. De allí la importancia de la reglamentación que brinde la legislación a la cooperativa de trabajo adquirente o continuadora de la explotación de la empresa en crisis, para la conservación de la empresa y la fuente laboral en beneficio de todos los sujetos interesados. No obstante ello, el sistema implementado por la ley concursal que pretende proteger al trabajador mediante el otorgamiento de privilegios en el proceso concursal individualmente considerado o como cooperativa de trabajo sigue planteando interrogantes al momento de afirmar si este es el mejor sistema para resolver la problemática del trabajador frente a la insolvencia empresarial.

Por último cabe preguntarse si lo óptimo, aunque perfectible, para garantizar los derechos del trabajador no deja de ser la creación del fondo de garantía.

De ésta manera la recuperación empresaria quedaría en manos de quienes revisten la calidad de empresarios y no en manos de trabajadores que carecen de capital y cuyo ánimo asociativo nace de la urgencia y no del sentido de pertenencia y solidaridad, valores propios del cooperativismo.

\section{5.- REFERENCIAS BIBLIOGRÁFICAS}

Alegría Héctor, (2008) Reglas y Principios del Derecho Comercial, Buenos Aires, La Ley.

Anich, Juan A., (2012) Cooperativas de trabajo en la legislación concursal, Buenos Aires, Astrea.

Borda, Guillermo A., (2008), Tratado de derecho civil. Parte general. Bs. As., La Ley.

Casadío Martínez, Claudio A., Los intereses de los créditos laborales ante el concurso preventivo, LL, 2006-D-492.

Cámara Héctor, La conservación de la empresa en las leyes de sociedades comerciales y de concursos, Revista de Derecho Empresario, $N^{\circ} 54$.

Chomer Héctor Osvaldo y Sicoli Jorge Silvio, (2011), Ley de concurso y quiebras, Buenos 
Aires, La Ley.

Dasso Ariel A., La ley de reforma de la ley de concursos y quiebras según ley 26.684. La observable constitucionalidad del "Cramdown" operativo, LL, 2011-C1247.

Galeano, Francesco, (1999), Derecho Comercial, T. I, Santa Fe de Bogotá Colombia, Editorial Temis.

Farinia, Juan M. - Farina Guillermo V., Concurso preventivo y quiebras, Bs. As., Astrea, 2008.

Favier Ddubois (H), Eduardo M., Reglamentaciones necesarias para la correcta aplicación de la reforma de la ley de quiebras, LL, 9/8/11.

Gebhardt, Marcelo, (2008) Ley de Concursos y quiebras, bs. As., Astrea.

Iglesias, José A., La filosofía del derecho de concurso y quiebras, LL 1995-E-1188.

Junyent Bas, Francisco, Análisis exegético de la reforma de la ley concursal en materia de relaciones laborales y cooperativas de trabajo, "Derecho Comercial del Consumidor y de la Empresa, $\mathrm{N}^{\circ} 3$.

Junyent Bas, Francisco y Molina Sandoval, Carlos A. (2012) "Ley de Concursos y Quiebras" comentada y actualizada.. Tomos I y II, Editorial, Buenos Aires, Abeledo Perrot.

LEY N ${ }^{\circ} 24.522$ de Concurso y Quiebras, (B.O. 07/08/2011).

LEY N ${ }^{\circ} 25.589$ (B.O. 16/05/2002).

LEY 26.684 (B.O 30/07/2011).

Mansueti, Hugo R., El privilegio del crédito laboral por accidente y el Convenio 173 de la OIT en el juicio de la Corte, Derecho Laboral y de la Seguridad Social, Abeledo Perrot, Volumen 15, agosto 2014.

Salas, Ana M. (2012) La interposición en el mercado laboral de las cooperativas de trabajo - Revista DDTrabajo. 
Rivera, Julio C., (2006) Estudios de Derecho privado, Santa Fe, Rubinzal Culzoni.

Rivera, Julio C., ROITMAN Horacio, VÍTOLO Daniel, (2000) Ley de concurso y quiebras, Santa Fe, Rubinzal Culzoni.

Rouillon, Adolfo, (2011) “Ley de Concursos y Quiebras” comentada, Buenos Aires, Lexis Nexis.

Rovira Alfredo L. (Dir.) (2005) "Empresa en Crisis", Buenos Aires, Astrea.

Tevez, Alejandra N., (2010) Empresas recuperadas y cooperativas de trabajo, Buenos Aires, Astrea.

Vazquez Vialard, Antonio, (2005) Ley de Contrato de Trabajo comentada y concordada, Santa Fe, Rubinzal Culzoni.

Vítolo, Daniel R., (2007) Concurso y Quiebras, Buenos Aires, Editorial Ad- Hoc.

Vítolo, Daniel R., La incorporación del salvataje cooperativo al régimen concursal, LL, 11/8/11.

\section{CURRICULUM VITAE}

\section{Silvana Soledad Ortiz}

Abogada. Especialista en Teoría y Técnica del Proceso Judicial. Doctorando en Derecho de la UNNE. Profesora Titular Derecho de la Empresa en Crisis y Directora del Proyecto de Investigación: "Los Derechos del Trabajador y la Cooperativa de Trabajo en la Ley de Concurso y Quiebras a partir de la reforma de la ley 26684: la inserción de derechos laborales en el sistema concursal”, Facultad de Ciencias Empresariales, Universidad de la Cuenca del Plata. Jefe de Trabajos Prácticos de la Facultad de Derecho y Ciencias Sociales y Políticas UNNE. Becaria de Investigación SGCyT UNNE.

silvanasortiz@hotmail.com 